\title{
Versatile externally modulated lasers technology for multiple telecommunication applications
}

\author{
Xing Dai, Helene Debregeas, Guillaume Da Rold, David Carrara, Kevin Louarn, \\ Elena Durán Valdeiglesias, and Francois Lelarge
}

\begin{abstract}
This paper presents our technological approach for Externally Modulated Lasers (EMLs), based on Semi-Insulating Buried Heterostructure (SIBH) waveguide. We use Gas Source Molecular Beam Epitaxy (GSMBE) to grow the Phosphorusbased multi-quantum wells for both laser and modulator sections with butt-joint integration. The same GSMBE grows the p-doped InP claddings with low-diffusion Be dopant, leading to an accurate control of doping profiles, ensuring very steep modulator extinction curves. We present the main EML design rules and compromises, then apply them to different EMLs aiming at major telecom and datacom applications. After presenting characteristics of the standard $10 \mathrm{~Gb} / \mathrm{s}$ C-band EML, we propose a $10 \mathrm{~Gb} / \mathrm{s}$ EML at $1577 \mathrm{~nm}$ for next generation access networks, with a record high $10.5 \mathrm{dBm}$ facet modulated power. Then we present high-speed EMLs up to 56 GBaud for datacenter interconnections, both in $\mathrm{O}$ - and $\mathrm{C}$-band, aiming at very low peak-to-peak modulation voltage $(<1.2 \mathrm{~V})$, high facet modulated power $(>4.4 \mathrm{dBm})$, and compatible with uncooled operation $\left(20\right.$ to $\left.70{ }^{\circ} \mathrm{C}\right)$. These results confirm the efficiency and versatility of this technological platform for EMLs in a broad range of applications.
\end{abstract}

Keywords-C-band, Electro-Absorption Modulated Laser (EML), O-band, uncooled.

\section{INTRODUCTION}

$\mathrm{W}$ ITH the extremely rapid growth of new services, particularly video and 5G, optical networks must evolve rapidly towards higher and higher speeds, and provide solutions adapted to each type of transmission. Long-distance transmissions use optical amplification and aim at the highest spectral density. To achieve this, they adopt a multitude of dense wavelength division multiplexing (DWDM) sources, with complex modulation formats in amplitude, phase and polarization (QPSK, QAM, ...), together with the signal processing to reconstruct the received signal using sophisticated error correction codes. The most common technological approach uses high-power InP continuous lasers, coupled into the photonic on silicon circuits, which allow modulation with complex formats, as well as passive functions such as multiplexing / demultiplexing, splitting... In reception, these complex formats require the use of a laser as a local

Manuscript received on July 29, 2020. This work was supported partially by the H2020-ECSEL-APPLAUSE 826588 project.

X. Dai, H. Debregeas, G. Da Rold, D. Carrara, K. Louarn, E. Durán Valdeiglesias and F. Lelarge are with Almae Technologies, Marcoussis, France (email: daisy.dai@almae-technologies.com). oscillator and several photodiodes in order to retrieve the amplitude and phase information of the signal.

For shorter distance transmissions, it is possible to use simple amplitude modulation such as NRZ or PAM4 for example. These formats require less complex components to generate the modulation, and can be detected by simple photodiodes. A first technological approach uses Directly Modulated Lasers (DMLs) where the optical power is varied via the current injected into the laser. This very simple and low-cost approach makes it possible to achieve high output power with low-power consumption. For very short distances of a few meters, e.g. in data centers, the most common solution is Vertical Cavity Emission Lasers (VCSELs) coupled into multimode fibers, which are very low cost to manufacture and package. For slightly longer distances up to $20 \mathrm{~km}$, edge-emitting Distributed Feedback (DFB) lasers coupled into a single-mode fiber are used. An optimized design of the quantum wells using Aluminium-based active material allows these lasers to operate over a very wide temperature range of about 100 degrees $\left(0\right.$ to $85^{\circ} \mathrm{C}$ typically). This uncooled operation, with no Peltier element, further reduces cost and power consumption.

However, the direct modulation of the laser, controlled by the injected electrical current, causes a variation in the density of electrical carriers and photons in the laser cavity. This changes the effective index of the optical mode, thus the emitted wavelength, which becomes different between 0 and 1 (adiabatic chirp). Moreover, these two effects interact and generate an oscillation phenomenon at a resonance frequency of the laser, in the order of a few GHz. An oscillation of the emitted power and wavelength is observed, especially when high modulation amplitudes are sought (extinction ratio > $5 \mathrm{~dB})$. In optical fiber, the different wavelengths propagate at slightly different speeds (chromatic dispersion). The phenomena of adiabatic chirp and relaxation oscillation therefore lead to strong degradation of the signal after propagation in the optical fiber. Therefore, DMLs are generally limited to O-band applications around $1300 \mathrm{~nm}$ where chromatic dispersion is the lowest, for uncooled applications such as in subscriber access networks to generate uplink signals. In recent years, much work has been done to increase the performance of DMLs, in particular by increasing the resonant frequency of the laser. For example, transmissions at 25 GBaud and even 56 GBaud PAM4 have been successfully demonstrated [1]. 

including reprinting/republishing this material for advertising or promotional purposes, creating new collective works, for resale or redistribution to servers or lists, or reuse of any copyrighted component of this work in other works.

For C-band applications where the chromatic dispersion of the optical fibers is higher, or for most high-speed applications (50 Gb/s and $100 \mathrm{~Gb} / \mathrm{s}$ ), the component used is the Electroabsorption Modulated Lasers (EML). It is deployed in particular for metropolitan area networks in C-band up to 80 $\mathrm{km}$, or in O-band for interconnection between data centers (distances of about $80 \mathrm{~km}$ in $4 \times 25 \mathrm{~Gb} / \mathrm{s}$, then $4 \times 100 \mathrm{~Gb} / \mathrm{s}$ PAM4), or within data centers (distances of less than $2 \mathrm{~km}$ in $4 \times 100 \mathrm{~Gb} / \mathrm{s}$ PAM 4 modulation, then $800 \mathrm{~Gb} / \mathrm{s}$ and probably in the future $1.6 \mathrm{~Tb} / \mathrm{s}$ ). The EML consists of a continuously operating DFB laser section monolithically integrated with an Electro-absorption Modulator (EAM) section. The EAM is a transparent section, which becomes absorbing when a reverse voltage is applied. Since the laser cavity emits continuously, there are no adiabatic chirp or relaxation oscillation effects in this case. Only a slight variation in wavelength appears at the transition between 0 and 1 , when the voltage in the modulator changes, thus changing the phase of the transmitted wave (transient chirp). The optical amplitude and frequency characteristics shown in Fig. 1 for a DML and an EML illustrate the difference in performance between the two approaches, and the possibility of obtaining better transmission performance with an EML.
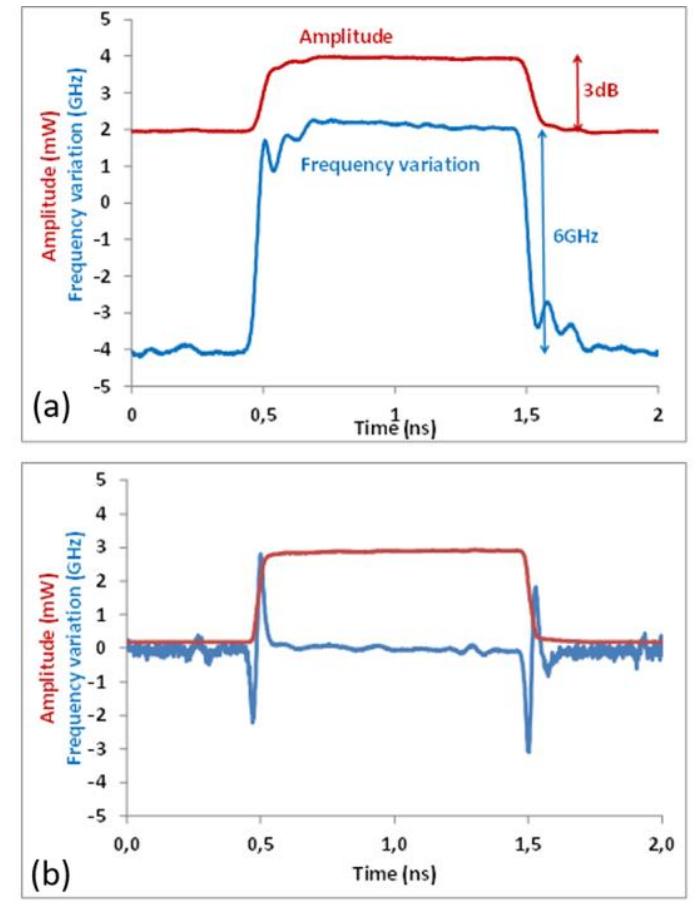

Fig. 1. Illustration of amplitude and frequency variations during a ' 1 ' bit for (a) a DML, (b) an EML.

Furthermore, since the EAM is reverse-biased, the modulation mechanism is no longer limited by the carrier injection speed, but by the carrier extraction efficiency under an electric field. This much faster phenomenon allows very high electro-optical bandwidths around 30-40 GHz, which can even approach $60 \mathrm{GHz}$.

On the other hand, EML requires more complex manufacturing and control, and can be power limited. In addition, the absorption characteristic of the EAM as a function of the applied voltage is highly temperature- dependent, which makes EMLs difficult to operate uncooled. Many laboratories have been working for years on the optimization of the EML, following different directions depending on the application: increase emitted power, increase modulation speed, reduce power consumption, and/or achieve uncooled operation.

This article presents the progress of our work on EMLs, and the results obtained for different types of applications. Section 2 presents in detail the operation of an EML, the design rules, and the different trade-offs to be taken into account. Section 3 describes our technological approach, its impact on performances, and details the manufacturing process. Section 4 shows how this optimized design has been applied to our Cband EMLs, at 10 or $25 \mathrm{~Gb} / \mathrm{s}$, for metropolitan DWDM applications up to $80 \mathrm{~km}$. Section 5 presents a $1577 \mathrm{~nm}$ EML for the $10 \mathrm{~Gb} / \mathrm{s}$ downlink of XGS-PON access networks, optimized for high power. Section 6 shows the latest C-band and O-band results for inter and intra-datacenter applications, aiming at increasing the throughput to 50 and $100 \mathrm{~Gb} / \mathrm{s}$ PAM4, and to be compatible for uncooled operation. Finally, section 7 presents new developments for the integration of EMLs into a complete subsystem by hybridization on silicon platforms.

\section{CONCEPTION}

The EML consists of a $400 \mu \mathrm{m}-$ long DFB section, monolithically integrated with a $200 \mu \mathrm{m}$-long modulator section, as shown in Fig. 2. The rear facet of the laser is high reflection (HR) coated at $90 \%$ to emit all the optical power from the front facet, and the front facet is anti-reflection (AR) coated at $0.01 \%$ to reduce optical feedback to the laser section. Both laser and modulator structures are composed of III-V material undoped multi quantum wells (MQWs) on InP substrate, sandwiched between $\mathrm{p}$ and $\mathrm{n}$-doped InP claddings, thereby forming a pin heterostructure.

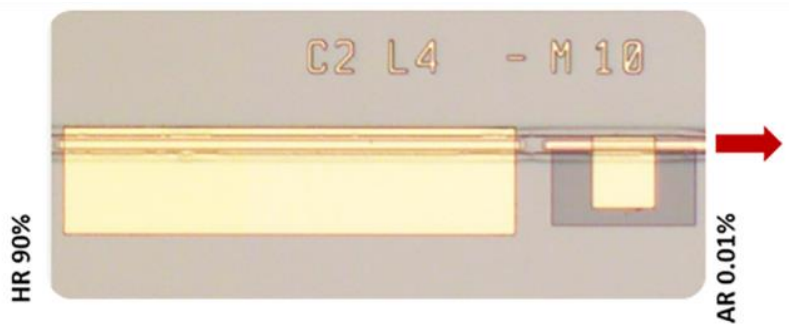

Fig. 2. Optical microscope photography of an EML.

The modulator section is an EAM, based on the Quantum Confined Stark Effect (QCSE) illustrated in Fig. 3a. The MQWs composition is chosen such that without electric field $\left(\mathrm{V}_{\mathrm{EAM}}=0 \mathrm{~V}\right)$ the MQWs bandgap energy is slightly higher (lower wavelength) than the energy of photons emitted by laser section: the modulator is in transparency mode. When applying a negative voltage on the modulator section, the resulting electric field in undoped MQWs modifies the bandgap structure and reduces the effective bandgap energy: the modulator becomes absorbing. The effect is illustrated in Fig. 3b, where the absorption spectrum of EAM shifts to lower energies when applying a reverse voltage. Fig. 3c shows the 

including reprinting/republishing this material for advertising or promotional purposes, creating new collective works, for resale or redistribution to servers or lists, or reuse of any copyrighted component of this work in other works.

resulting absorption of modulator section versus applied voltage (extinction curve) for various laser emission wavelengths, showing a steep absorption of more than $15 \mathrm{~dB}$ at $-1 \mathrm{~V}$ to $-2 \mathrm{~V}$. Higher laser emission wavelength $(\lambda 4)$, that is lower energy, requires more voltage to reach maximum extinction. Quantification effect in the wells creates a bounding of electron-hole pairs called exciton: this generates the step-like shape of the absorption, with even a local peak spike at absorption front (Fig. 3b). With applied electrical field, holes and electrons wavefunctions overlap decreases, leading to a damping of exciton peak. The exciton is visible as well with the local sharp minimum in the ER(V) curve (Fig. $3 c)$, and helps to obtain steep extinction curve.

An ideal modulator should be fully transparent at $0 \mathrm{~V}$ (no insertion losses), have a steep extinction curve (low peak-topeak modulation voltage $\mathrm{V}_{\mathrm{pp}}$ ), and sufficient extinction (typically around $15 \mathrm{~dB}$, but variable depending on the application). Several parameters allow the structure to be optimized, as presented below.
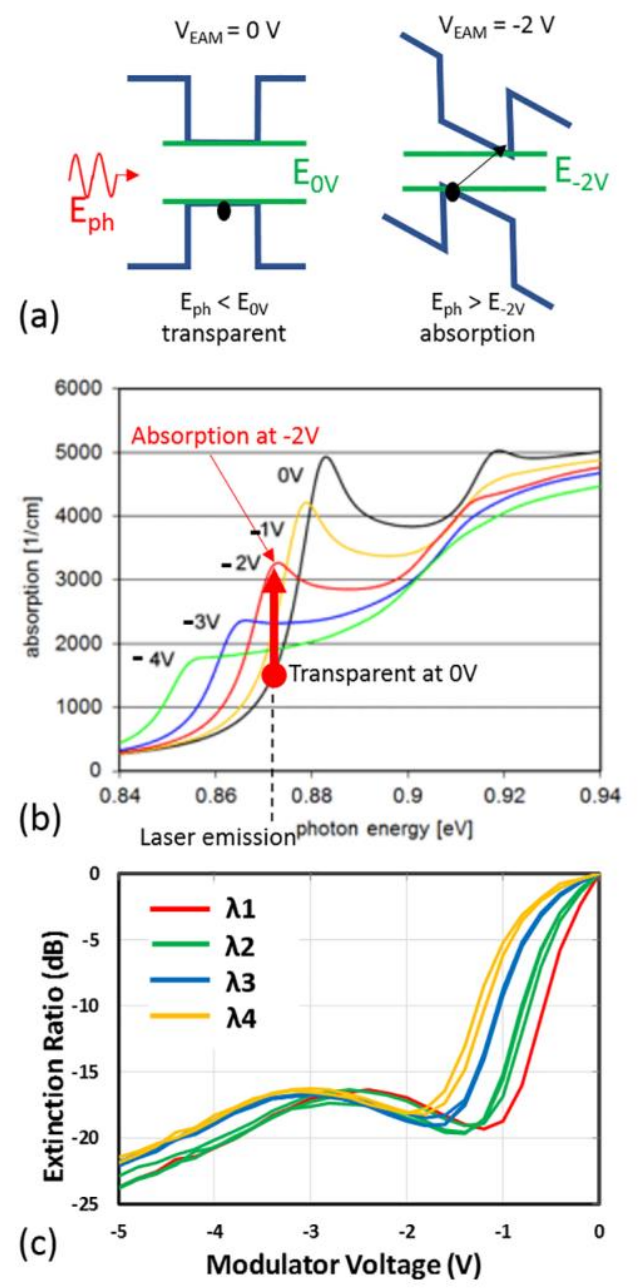

Fig. 3. (a) Principle of QCSE, (b) absorption vs wavelength characteristics for different applied negative voltages, (c) resulting extinction curve of an EAM section for different laser emission wavelengths.

The detuning $\Delta \lambda$ between laser emission wavelength and modulator absorption peak wavelength is a key parameter, as shown in Fig. 3c. A low detuning ( $\lambda 1)$ allows to obtain a very steep extinction but generates insertion losses. This case is adapted to very low power consumption applications with $\mathrm{V}_{\mathrm{pp}}$ around $1.2 \mathrm{~V}$ (datacenters for example). On the other hand, high detuning $(\lambda 4)$ reduces losses but increases $V_{p p}$ to almost $2 \mathrm{~V}$. Thus, it is preferred for high-power applications (e.g. access networks). Typically, the detuning $\Delta \lambda$ varies between $40 \mathrm{~nm}$ and $60 \mathrm{~nm}$.

The thickness of each quantum well also has an important impact. Indeed, the energy shift of absorption front is proportional to $E^{2} *\left(m_{e}+m_{h h}\right) * t h_{Q W}{ }^{4}$, where $\mathrm{E}$ is the applied electric field, $m_{e}$ and $m_{h h}$ are the effective masses of electrons and holes, and thew is the quantum wells thickness. In one sense, it is preferable to increase the thickness of quantum wells. But this also reduces the exciton strength, especially under the application of an electric field where the overlap of the wave functions of holes and electrons decreases faster for thick QWs: the extinction curve becomes smoother. The optimum thickness of the quantum well therefore corresponds to the maximum thickness that still guarantees sufficient confinement of the exciton, typically around $9 \mathrm{~nm}$.

Finally, composition of the MQWs is key, and its optimization has been the subject of numerous studies [2], [3], [4]. In order to increase the exciton effect, it is necessary to have highly confined quantum wells with a high barrier height. But this can lead to absorption saturation problems. Under high injected power, photogenerated carriers in the MQW stack of the modulator tend to pile-up, due to their limited sweep-out time, especially for the holes with a higher effective mass and lower mobility. Firstly, this effect prevents the absorption of other photons because energy levels are occupied. Secondly it screens the applied electric field, which is therefore no longer efficiently applied to the MQWs. The ideal structure would therefore have a high conduction band offset $\left(\Delta \mathrm{E}_{\mathrm{C}}\right)$ for strong electrons confinement, and a low valence band offset $\left(\Delta \mathrm{E}_{\mathrm{V}}\right)$ for fast holes sweep-out time. In the InGaAsP-based system, the ratio $\Delta \mathrm{E}_{\mathrm{C}} / \Delta \mathrm{E}_{\mathrm{V}}$ is around $40 \%: 60$ $\%$. The optimization then consists in choosing a barrier height just sufficient to maintain a strong exciton under electrical field. We typically use InGaAsP with $1.17 \mu \mathrm{m}$ photoluminescence (PL) for modulators operating at $1.55 \mu \mathrm{m}$, and the barrier with lower PL for modulators operating at 1.3 $\mu \mathrm{m}$. In addition, tensile strain can be applied to quantum wells such that the first level of valence band is filled by light holes instead of heavy holes, as light holes have the advantage of faster sweep-out time, and stronger exciton link [5].

To further optimize the ratio $\Delta \mathrm{E}_{\mathrm{C}} / \Delta \mathrm{E}_{\mathrm{V}}$ and to favour uncooled application, many laboratories grow Aluminiumbased quantum wells, where the ratio $\Delta \mathrm{E}_{\mathrm{C}} / \Delta \mathrm{E}_{\mathrm{V}}$ is higher at 70 $\%$ : $30 \%$ [5], [6], [7]. However, as Aluminium-based materials which are prone to well-known oxidation issues, they present some constrains in terms of processing compared to Phosphorus-based materials.

Once the structure of the MQW modulators has been chosen, the geometry is adapted according to target specifications, in particular modulation rate and extinction ratio (ER). Under modulation between a voltage $\mathrm{V}_{\text {on }}$ for bits 1 and $V_{\text {off }}$ for bits 0 , the ER is defined as the ratio between the $\mathrm{ON}$ and OFF powers and is expressed by: 


$$
E R(d B)=10 \log \left(P_{o n} / P_{o f f}\right)=10 \log (\exp (-\Gamma \Delta \alpha L))
$$

where $\Gamma$ is the mode optical confinement in the MQWs, $\Delta \alpha$ is the variation of absorption coefficient in the MQWs per unit length between $\mathrm{V}_{\text {on }}$ and $\mathrm{V}_{\text {off }}$, and $\mathrm{L}$ is the length of modulator. Therefore, ER is proportional in $\mathrm{dB}$ to the product $\Gamma \Delta \alpha \mathrm{L}$.

The choice of modulator length is mainly imposed by the desired modulation rate which defines the minimum electrooptical bandwidth at $3 \mathrm{~dB}\left(\mathrm{f}_{3 \mathrm{~dB}}\right)$ to obtain a clean eye diagram. For example, for $10 \mathrm{~Gb} / \mathrm{s}$ (resp $25 \mathrm{~Gb} / \mathrm{s}$ ) NRZ modulation the MEA must have a $\mathrm{f}_{3 \mathrm{~dB}}$ around $8 \mathrm{GHz}$ (resp $17 \mathrm{GHz}$ ). For PAM4 modulation at 28 GBaud (resp 56 GBaud) a $\mathrm{f}_{3 \mathrm{~dB}}$ of 20 $\mathrm{GHz}$ (resp $35 \mathrm{GHz}$ ) will be targeted. Fig. 4 shows a picture of EML soldered on submount, with the electrical connections. Electrical ground is obtained via the solder of the EML underside. The laser electrode is connected to a simple static pad. The modulator electrode is connected to a high frequency (HF) line sandwiched between two ground areas. A $50 \Omega$ resistor is connected in parallel to provide impedance matching with the signal generator. Using a simple equivalent circuit, $\mathrm{f}_{3 \mathrm{~dB}}$ can be expressed as:

$$
\begin{aligned}
& f_{3 d B}=\frac{1}{2 \pi\left(R_{S}+\left(\frac{1}{R_{g}}+\frac{1}{R_{L}}\right)^{-1}\right) c} \\
& \text { with } C=C_{j}+C_{p a r}+C_{p a d}
\end{aligned}
$$

where $R_{g}$ is the impedance of the voltage generator connected to the EAM, which normally has a value of $50 \Omega$. The load resistance $R_{L}$ is the $50 \Omega$ parallel matching resistance added on the submount. The EAM part includes a series resistance $R_{\mathrm{s}}$ (typically several ohms), and a capacitance $\mathrm{C}$ which is the sum of the reverse biased $p-i-n$ junction capacitance $C_{j}$, parasitic capacitance $\mathrm{C}_{\text {par }}$ and pad capacitance $\mathrm{C}_{\text {pad }}$. In order to increase the $3 \mathrm{~dB}$ bandwidth, one needs to reduce the capacitance $\mathrm{C}$. The pad capacitance can be reduced by using small pad (minimum $60 \mu \mathrm{m} \times 60 \mu \mathrm{m}$ for wire bonding compatibility) and a thick dielectric layer under metallization, leading to typically $0.1 \mathrm{pF}$ for $\mathrm{C}_{\text {pad }}$. The junction capacitance is expressed by $C_{j}=\varepsilon_{0} \varepsilon_{r} w L / d$, where $\varepsilon_{0}$ is vacuum permittivity, $\varepsilon_{\mathrm{r}}$ is undoped MQW structure relative permittivity around $12.5, \mathrm{~L}$ is modulator length, and $\mathrm{d}$ is undoped layers thickness. Increasing $\mathrm{d}$ is detrimental because for a given voltage $\mathrm{V}$, the electric field applied on MQWs is $\mathrm{E}=\mathrm{V} / \mathrm{d}$. Thus, increasing $\mathrm{d}$ would directly increase the required $\mathrm{V}_{\mathrm{pp}}$. Therefore, modulator length is the main parameter to be adapted according to the required bandwidth. Typically, modulator length is in the range of $200 \mu \mathrm{m}$ for $10 \mathrm{~Gb} / \mathrm{s}, 150 \mu \mathrm{m}$ for $25 \mathrm{~Gb} / \mathrm{s}$ or 25 GBaud, and $100 \mu \mathrm{m}$ for 56 GBaud.

Then, the confinement $\Gamma$ in MQWs is adjusted to reach the required ER, by adapting the number of MQW: typically $10 \%$ confinement for $10 \mathrm{~Gb} / \mathrm{s}$, and beyond $15 \%$ for more than 25 $\mathrm{Gb} / \mathrm{s}$ depending on the ER specifications. The price for higher confinement is an increase of undoped MQWs layer thickness $\mathrm{d}$, leading to a higher $\mathrm{V}_{\mathrm{pp}}$. For most applications, $\mathrm{V}_{\mathrm{pp}}$ may be up to $2 \mathrm{~V}$, but for intra-datacenters as described in section 6, it is preferred to keep very low $\mathrm{V}_{\mathrm{pp}}$ at $0.8 \mathrm{~V}$ to reduce electrical consumption, with a moderate extinction ratio of $3.5 \mathrm{~dB}$.
Therefore, in practical designs, the thickness of undoped region and the length of modulator should be compromised to simultaneously optimize three parameters: $E R, f_{3 \mathrm{~dB}}$, and $\mathrm{V}_{\mathrm{pp}}$.

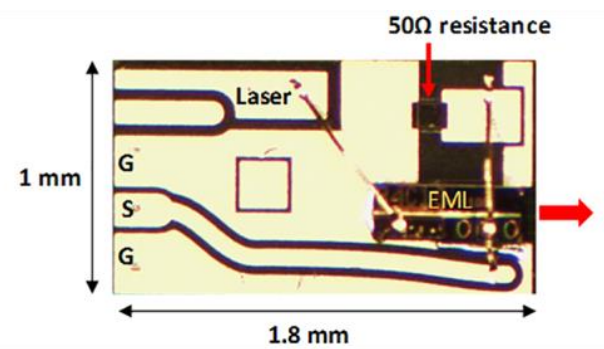

Fig. 4. Photography of an EML mounted on submount, with electrical connections.

As explained in the introduction, the main advantage of EML over DML is the absence of modulation of the laser section, thus the absence of relaxation oscillations of the laser section. However, the EML is extremely sensitive to modulated optical feedback after the modulator section, as it would excite the laser at its resonant frequency and severely degrade the eye diagrams. A feedback smaller than $0.01 \%$ ( -40 $\mathrm{dB}$ ) becomes necessary to prevent laser parasitic oscillation. Feedback from the optical system (fiber connectors, couplers, multiplexers, ...) is suppressed by integrating an isolator in the subassembly right at the output of the EML. But feedback from the chip output facet must be suppressed as well. A bilayer $\mathrm{TiO}_{2} / \mathrm{SiO}_{2}$ anti-reflection coating is applied on the output facet, which can provide down to $0.01 \%$ reflectivity. But for higher tolerance to coating quality and thereby higher industrial yield, the waveguide can be modified as well to avoid the small amount of reflected light to couple back into the waveguide. A first approach is to use a window section [8], that is a section without waveguiding as illustrated Fig. 5a. With a $25 \mu \mathrm{m}$-long window, optical feedback is reduced by about 1:6. The other solution is to tilt the output waveguide [9], as illustrated in Fig. 5b, which reduces feedback by about $1: 15$ for a $7^{\circ}$ tilt. Both approaches can be combined, with tilt and window, leading to feedback reduction of 1:100.

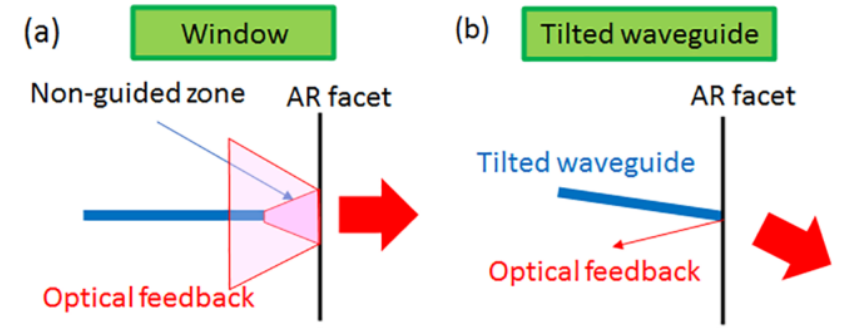

Fig. 5. Schematics. (a) Straight waveguide with window, (b) Tilted waveguide.

To increase the optical power coupled into the fiber at the output of EML, an important parameter is the shape and divergence of the optical mode. It is possible to integrate a Spot Size Converter (SSC) at the output of the EML, allowing the shape of the mode to be progressively modified to reach a larger diameter and a reduced divergence. Our buried technology, presented in the following paragraph, allows to have a circular mode (divergence $22^{\circ} \times 24^{\circ}$ ), and to enlarge it very simply by reducing the waveguide width, with a divergence of $16^{\circ} \times 18^{\circ}$ obtained by a narrowing of the ribbon 
including reprinting/republishing this material for advertising or promotional purposes, creating new collective works, for resale or redistribution to servers or lists, or reuse of any copyrighted component of this work in other works.

to $0.7 \mu \mathrm{m}$. By using the modulator material, this $75 \mu \mathrm{m}$-long SSC does not bring any additional losses.

\section{EPITAXY AND FABRICATION PROCESS}

Different integration technologies like Quantum Well Intermixing, Selective Area Growth, or Butt Joint Regrowth [10] enable the monolithic integration of different active and passive components while minimizing the impact on the performance of individual components. Almae Technologies uses the widely known butt-joint (BJ) technology because it allows independent optimization of quantum wells in both sections: material composition, doping, number of MQWs and thickness.

Almae technologies employs the InGaAsP material system grown by GSMBE for the MQWs, using a Riber V100 multi 3-inch MBE reactor. Solid sources are used for III elements (In, Ga) whereas $\mathrm{V}$ elements $\mathrm{As}_{2}$ and $\mathrm{P}_{2}$ molecules stem from the decomposition of $\mathrm{AsH}_{3}$ and $\mathrm{PH}_{3}$ gas using a gas cracker. Using gas sources instead of solid sources for elements $\mathrm{V}$ enables to do abrupt interface and reproductible layers with different As/P ratio by simply adjusting the $\mathrm{PH}_{3}$ and $\mathrm{AsH}_{3}$ flow during a short time of growth stop $(\sim 10 \mathrm{sec})$, which is of main importance for the controlled growth of MQWs. Thus, a simple and reproductible method for the growth of InGaAsP MQW by GSMBE is to work with constant element III (fixed $\mathrm{In} / \mathrm{Ga}$ ratio) and adjust the $\mathrm{V}$ element (variable As/P ratio) between the well and the barrier. Moreover, as the wells are compressively strained due to their lattice-mismatch $(\sim 1 \%)$, strain compensation with tensile strained barriers is useful to prevent the formation of crystalline defects [11].

Once the EAM heterostructure is grown on an InP substrate, a $\mathrm{SiO}_{2}$ layer is deposited by Plasma-Enhanced Chemical Vapor Deposition (PECVD) and patterned by Reactive Ion Etching (RIE). This patterned $\mathrm{SiO}_{2}$ is used as a hard mask to define trenches into the EAM vertical structure by chlorine based Inductively Coupled Plasma (ICP). Cleaning and restoration of the surfaces are achieved by a succession of wet etch steps before GSMBE regrowth of the laser vertical structure in the previously ICP etched trenches.

GSMBE presents some advantage over MOVPE for the BJ technology. The anisotropy of molecular beams and the insensitivity of MBE to Selective Area Growth (SAG) effects in the vicinity of the $\mathrm{SiO}_{2}$ mask make it easier to control the butt-joint regrowth step compared to MOVPE, for which the strategy for EML epitaxial growth is rather to take advantages of SAG effects [12]. As illustrated in Fig. 6, under optimized growth conditions, GSMBE deposits polycrystals on top of the $\mathrm{SiO}_{2}$ mask, which are removed through lift-off, leading to an abrupt interface between the laser and the modulator sections.

Precise vertical alignment of the EAM and Laser MQWs as well as similar effective index for both regions are mandatory to limit the scattering and reflection losses at butt-joint interfaces.

In order to obtain a DFB laser, Electron beam (E-beam) lithography is used to pattern a Bragg grating in a dedicated layer on top of the laser structure. The grating pitch is adapted according to the desired wavelength. After an ICP etching of the grating layer, grating teeth are filled by $300 \mathrm{~nm}$ of p-doped InP grown by GSMBE for planarization (Fig. 7a).

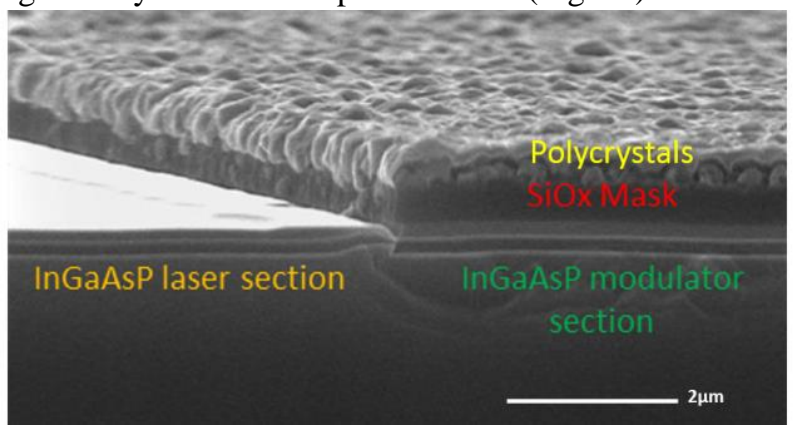

Fig. 6. SEM cross-section observation of a BJ regrowth done at Almae technology, showing the laser and the modulator sections.

Afterwards, waveguides are defined by optical contact lithography and then etched by ICP. Semi Insulated Buried Heterostructure (SIBH) regrowth performed by MOVPE is used to laterally bury the waveguide with iron doped semiinsulating InP (Fig. 7b), which prevents lateral leakage current and allows an efficient thermal dissipation, high speed modulation compatibility, circular optical mode and chip mechanical robustness.

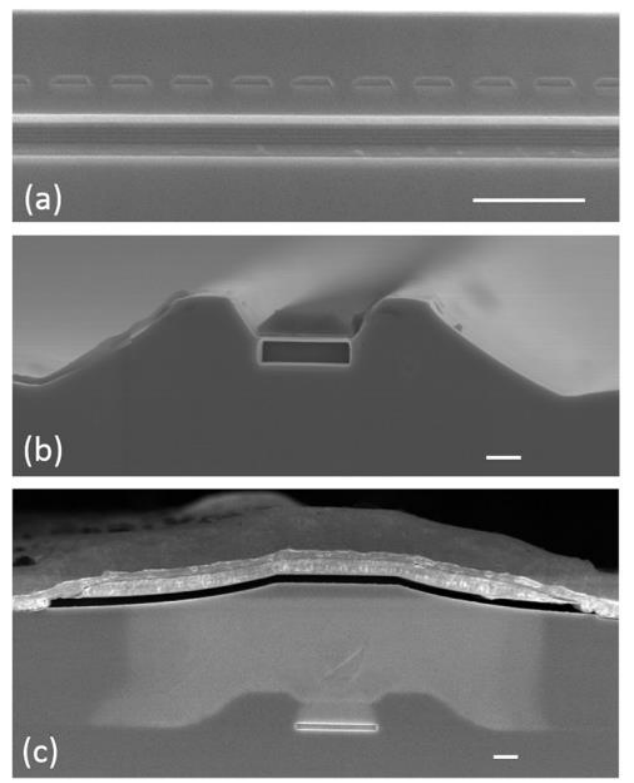

Fig. 7. Cross-sectional SEM images of (a) buried grating layer, (b) SIBH regrowth with $\mathrm{SiO}_{2}$ mask, and (c) final device. Scale bar: $500 \mathrm{~nm}$.

Afterwards, GSMBE is used to grow the final cladding layer composed of P-doped InP and a ternary contact layer. The possibility of using Beryllium p-type dopant with GSMBE instead of Zinc dopant in MOVPE is of main interest for the $\mathrm{P}$ regrowth steps in the EML process. Indeed, the nature of the dopant species and the lower temperature of the MBE growth of InP $\left(\sim 450{ }^{\circ} \mathrm{C}\right)$ than MOVPE growth $(\sim 650$ ${ }^{\circ} \mathrm{C}$ ) enable to limit dopants diffusion into the MQWs by substitutional-interstitial diffusion mechanisms [13]. The lower diffusion of $\mathrm{Be}$ dopant during the $\mathrm{P}$ cladding regrowth by GSMBE will allow to ensure a fully non-doped MQWs stack leading to a uniform application of the dielectric field (Poisson's law) along all the MQWs. Therefore, as illustrated in Fig. 8, we obtain a stepper EAM extinction response 

including reprinting/republishing this material for advertising or promotional purposes, creating new collective works, for resale or redistribution to servers or lists, or reuse of any copyrighted component of this work in other works. compared to $\mathrm{Zn}$ based $\mathrm{P}$ cladding regrowth by MOVPE.

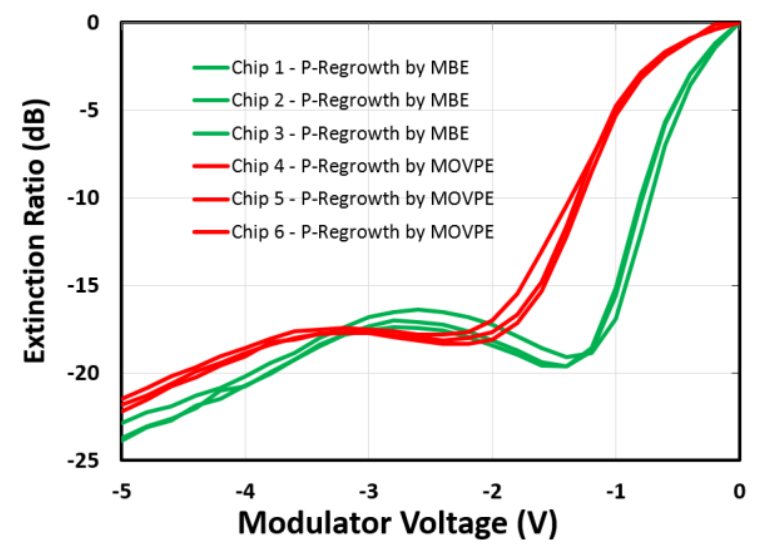

Fig. 8. EAM extinction response of EMLs with Zn P-doped cladding by MOVPE (in red) and with Be P-doped cladding by MBE (in green).

Metal contacts on the P-side are then defined by a lift-off process of Platinum / Gold deposited by electron beam evaporation. A $390{ }^{\circ} \mathrm{C}$ Rapid Thermal Annealing (RTA) permits diffusion of the Pt into the ternary contact layer to ensure an ohmic electrical contact and prevent gold diffusion into the semiconductor.

To reduce modulator capacitance and to electrically isolate laser and modulator sections, $\mathrm{H}+$ ions are locally implanted, turning top p-InP into insulating material. An ICP etching step of the ternary contact layer completes this implantation by physically isolating the EAM from the DFB.

To prevent parasitic capacitance of the EAM electrodes, a 2 $\mu \mathrm{m}$-thick $\mathrm{SiO}_{2}$ layer is deposited by PECVD and patterned by RIE to define a $\mathrm{SiO}_{2}$ pad below the EAM interconnection contact. That low capacitance pad coupled with SIBH regrowth technology allows to achieve high modulation bandwidth for the modulator. The next process step consists in depositing interconnection metal pads for laser and modulator to ease wire bonding of the EML electrodes during packaging steps (Fig. 7c).

The InP substrate is then thinned down to ensure precise cleaving of the optoelectronic devices while preventing damage on their optical facets. A Titanium / Platinum / Gold stack is then evaporated on the wafer $\mathrm{N}$-side to define the $\mathrm{N}$ type metallic contact.

\section{EML FOR 1550 NM AND 1577 NM APPLICATIONS}

\section{A. C-band 10 and $25 \mathrm{~Gb} / \mathrm{s} E M L$}

A first field of application of EML is C-band transmission for metropolitan networks. Modulation at a moderate rate of $10 \mathrm{~Gb} / \mathrm{s}$ is utilized in order to reach distances of 40 to $80 \mathrm{~km}$ despite the chromatic dispersion of the fibers. A high total data rate can be achieved by DWDM, with 40 channels spaced at $100 \mathrm{GHz}$ (0.8 nm wavelength), or 80 channels spaced at 50 $\mathrm{GHz}(0.4 \mathrm{~nm})$, covering the entire C-band (about 1525-1565 $\mathrm{nm}$ ). These applications typically require operation at $45{ }^{\circ} \mathrm{C}$ to reduce Peltier consumption, on-chip facet average modulated power $\left(\mathrm{P}_{\text {ave }}\right)$ of $4 \mathrm{dBm}$, with a $9 \mathrm{~dB}$ dynamic extinction ratio (DER) and a peak-to-peak modulation voltage $\left(\mathrm{V}_{\mathrm{pp}}\right)$ of less than $2 \mathrm{~V}$.
These EMLs benefit from our steep extinction curves. The detuning $\Delta \lambda$ between the laser emission wavelength and the absorption front of the modulator is minimized to about $45 \mathrm{~nm}$ in order to reduce $\mathrm{V}_{\mathrm{pp}}$, while maintaining low insertion losses at $\mathrm{V}_{\mathrm{EAM}}=0 \mathrm{~V}$.

The characteristic performance at $45^{\circ} \mathrm{C}$ is shown in Fig. 9ae. Fig. 9a shows the facet power and voltage as a function of laser current when the modulator is at $0 \mathrm{~V}$. A laser power larger to $10 \mathrm{~mW}$ is reached at $70 \mathrm{~mA}$, with a low $3.6 \Omega$ serial resistance. The optical spectrum is shown in Fig. $9 \mathrm{~b}$ with $\mathrm{I}_{\text {laser }}$ $=70 \mathrm{~mA}$, yielding single mode operation and Side Mode Suppression Ratio (SMSR) beyond $50 \mathrm{~dB}$. Fig. 9c shows the modulator ER as a function of the modulator voltage when $\mathrm{I}_{\text {laser }}=70 \mathrm{~mA}$. A $17 \mathrm{~dB}$ maximum ER is obtained for $\mathrm{V}_{\mathrm{EAM}}=$ $1.3 \mathrm{~V}$. The dynamic characterization of this device is shown in Fig. 9d-e. In Fig. 9d the electro-optical bandwidth of the device is represented when $\mathrm{I}_{\text {laser }}=70 \mathrm{~mA}$ and $\mathrm{V}_{\text {EAM }}=-0.5 \mathrm{~V}$. Under these conditions a $\mathrm{f}_{3 \mathrm{~dB}}$ of $18 \mathrm{GHz}$ is reached, largely fulfilling the requirements for $10 \mathrm{~Gb} / \mathrm{s}$ applications. Fig. 9e shows the eye diagram for a bit rate of $10 \mathrm{~Gb} / \mathrm{s}$ with $\mathrm{I}_{\text {laser }}=70$ $\mathrm{mA}$ and $\mathrm{V}_{\mathrm{EAM}}=1.5 \mathrm{~V}$. All the characteristics required for metropolitan application are obtained, with $\mathrm{P}_{\mathrm{ave}}=7 \mathrm{dBm}$, and a dynamic extinction ratio (DER) of $12.3 \mathrm{~dB}$. The e-beam technique used for DFB laser gratings writing allows to cover $5 \mathrm{~nm}$ wavelength range on a single wafer, which is a key economical asset when needing to cover the whole C-band. With a bandwidth of $18 \mathrm{GHz}$, these components can even be used for shorter-distance applications of the order of $10 \mathrm{~km}$, e.g. in access networks at data rates of $25 \mathrm{~Gb} / \mathrm{s}$ [14].
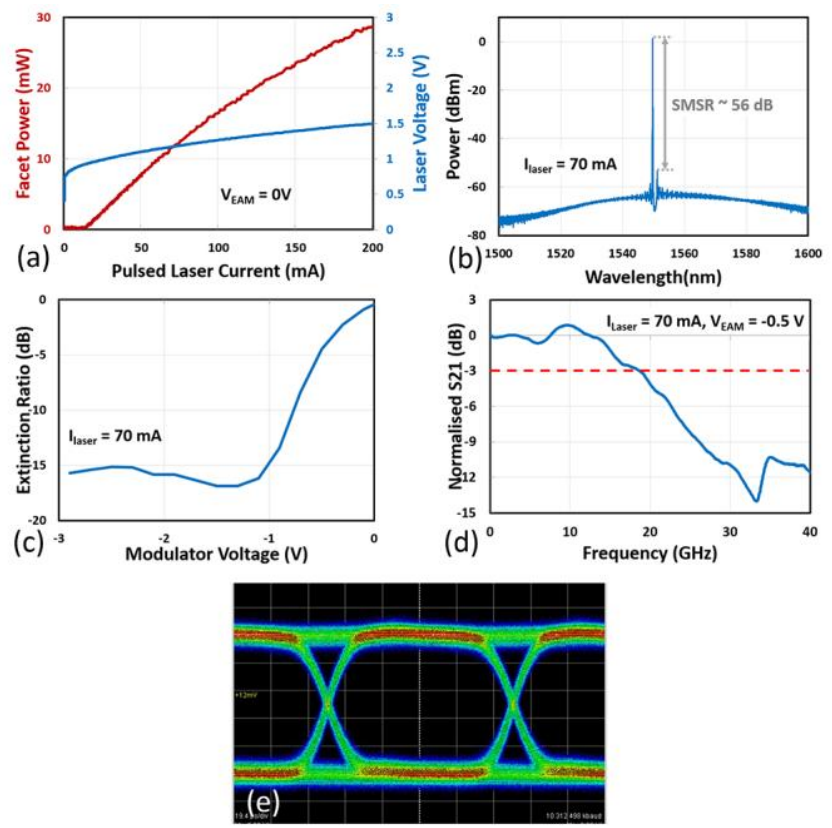

Fig. 9. Measurements of a $10 \mathrm{~Gb} / \mathrm{s}$ DWDM C-band EML at $45^{\circ} \mathrm{C}$. (a) Facet power and voltage versus laser current (pulsed). (b) Optical spectrum at 70 $\mathrm{mA}$. (c) Modulator steep extinction curve at $\mathrm{I}_{\text {laser }}=70 \mathrm{~mA}$. (d) ElectroOptical bandwidth of modulator at $\mathrm{I}_{\text {laser }}=70 \mathrm{~mA}$ and $\mathrm{V}_{\text {EAM }}=-0.5 \mathrm{~V}$. (e) Eye diagram at $10 \mathrm{~Gb} / \mathrm{s}$ for $\mathrm{I}_{\text {laser }}=70 \mathrm{~mA}$ and $\mathrm{V}_{\mathrm{pp}}=1.5 \mathrm{~V}$.

These components, currently in production at Almae Technologies, systematically endure a burn-in with stressful conditions $\left(\mathrm{I}_{\text {laser }}=175 \mathrm{~mA} / \mathrm{V}_{\mathrm{EAM}}=-1 \mathrm{~V} / 100{ }^{\circ} \mathrm{C} / 18 \mathrm{~h}\right)$, in order to eliminate youth defects and fragile devices. Then the 
or lists, or reuse of any copyrighted component of this work in other works.

design was qualified by subjecting a large batch of chips to accelerated ageing $\left(\mathrm{I}_{\text {laser }}=100 \mathrm{~mA} / \mathrm{V}_{\text {EAM }}=-1 \mathrm{~V} / 85^{\circ} \mathrm{C} /\right.$ $5000 \mathrm{~h}$ ). Considering a total acceleration factor of 50 , this corresponds to an operating life of $70 \mathrm{~mA} / 45^{\circ} \mathrm{C}$ of more than 25 years.

\section{B. 1577nm high-power EMLs for access networks}

Access networks are the final link between the Optical Line Terminal (OLT) of the network, and the Optical Network Unit (ONU) at the user's side, which can be a private house, a building, a company, a public building, ... These access networks have developed extremely fast, in particular with smartphones, 4G, and now 5G. Covering typical distances of 20 to $40 \mathrm{~km}$, they are based on Passive Optical Networks (PON), i.e. networks without optical amplification, but only with splitters / combiners or multiplexers / demultiplexers. The main constraint on the optical components is therefore to reach the power budget of the link, typically around $30 \mathrm{~dB}$. For this, the system is based on high-power transmitters, and on high sensitivity avalanche photodiodes (APDs) receivers. The second constraint is the cost, especially for components located at the ONU subscriber's premises.

The Full Service Access Network (FSAN) group proposes a GPON (Gigabit PON) evolution roadmap, and ITU standards have been defined for two approaches: NG-PON2 which is a wavelength division multiplexed system, or XGS-PON with $10 \mathrm{~Gb} / \mathrm{s}$ downstream and upstream data rates [15], [16]. Access networks must enable the coexistence of different standards on the same links, despite their specific data rates and slightly different wavelength ranges. A typical network link is shown in Fig. 10. For upstream, the wavelengths are Oband, around 1260-1280 nm for XGS-PON and $1310 \mathrm{~nm}$ for GPON. Low chromatic dispersion allows the employment of low-cost DMLs, at $2.5 \mathrm{~Gb} / \mathrm{s}$ or $10 \mathrm{~Gb} / \mathrm{s}$, in the ONU. For downstream, the wavelengths are $1577 \mathrm{~nm}$ for XGS-PON and $1490 \mathrm{~nm}$ for GPON, which requires the use of EMLs at the OLT to transmit despite the chromatic dispersion. The multitude of users is served via splitters and combiners, leading to a high-power budget in the range of 29 to $35 \mathrm{~dB}$ depending on network characteristics (link distances, number of users).

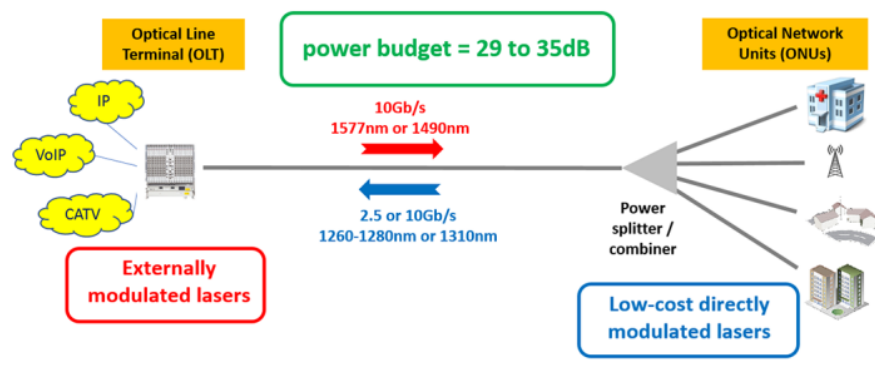

Fig. 10. Schematic of next generation PON network.

XGS-PON networks therefore require a high-power EML transmitting at $1577 \mathrm{~nm}$, used in the OLT. The EML is packaged in a Bi-directional Optical Sub-Assembly (BOSA) module shown in Fig. 11, which contains both the EML transmitter and APD receiver. Two transmitter power classes, called N1 and N2, are standardized for different optical budget ranges. Class N1 requires BOSA transmitter power from 2 to 6 $\mathrm{dBm}$, and class $\mathrm{N} 2$ from 4 to $8 \mathrm{dBm}$. Considering assembly losses about $4.5 \mathrm{~dB}$ in BOSA, this corresponds to EML facet modulated power $\mathrm{P}_{\text {ave }}$ higher than $6.5 \mathrm{dBm}$ for $\mathrm{N} 1$ and 8.5 $\mathrm{dBm}$ for $\mathrm{N} 2$.

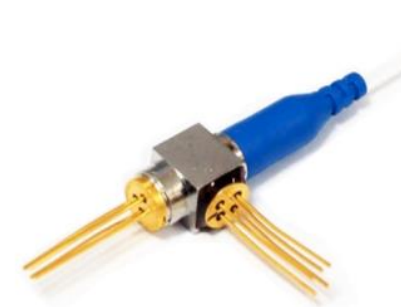

Fig. 11. Photography of a BOSA module, containing both $1577 \mathrm{~nm}$ transmitter and O-band APD receiver.

For this purpose, we have developed a specific high-power EML design with the same $200 \mu \mathrm{m}$-long EAM section, but with a $10 \mathrm{~nm}$ wider laser - modulator detuning $\Delta \lambda$, in order to minimize insertion losses by the modulator. The results at 45 ${ }^{\circ} \mathrm{C}$ are presented in Fig. 12. Fig. 12a shows the ER as a function of modulator voltage at $\mathrm{I}_{\text {laser }}=70 \mathrm{~mA}$. As detuning $\lambda 1$ has been increased, the maximum $17 \mathrm{~dB}$ ER is obtained for a slightly larger voltage of $-1.6 \mathrm{~V}$. Fig. $12 \mathrm{~b}$ shows the eye diagram at $10 \mathrm{~Gb} / \mathrm{s}$, with $\mathrm{V}_{\mathrm{pp}}=2.5 \mathrm{~V}$, at $\mathrm{I}_{\text {laser }}=100 \mathrm{~mA}$, demonstrating a DER of $12.4 \mathrm{~dB}$ and $\mathrm{P}_{\text {ave }}$ of $8 \mathrm{dBm}$, compatible with $\mathrm{N} 1$ and $\mathrm{N} 2$ applications.
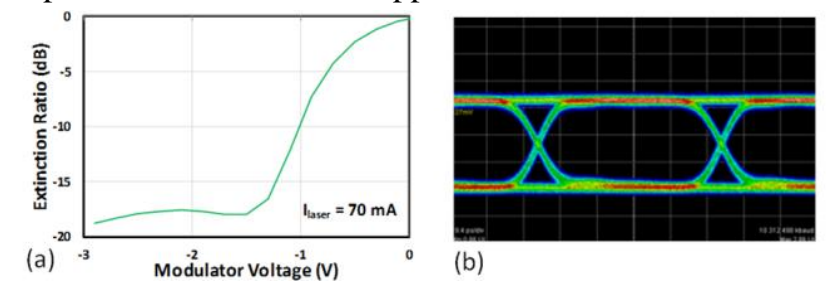

Fig. 12. (a) Static ER for an EMLs with a $200 \mu \mathrm{m}$-long EAM at $45^{\circ} \mathrm{C}$. (b) 10 $\mathrm{Gb} / \mathrm{s}$ eye diagram with $\mathrm{I}_{\text {laser }}=100 \mathrm{~mA}$ and $\mathrm{V}_{\text {EAM }}=2.5 \mathrm{~V}$ at $45^{\circ} \mathrm{C}$.

In order to further increase the number of users per OLT and/or to cover larger geographical areas, a new standard with higher optical budget appears. This is the class E1, with a power emitted by the BOSA of 6 to $9 \mathrm{dBm}$, corresponding to $\mathrm{P}_{\text {ave }}$ greater than $10.5 \mathrm{dBm}$. To achieve this, the first step is to increase the power emitted by the laser by using a higher current, but this leads to a modulator saturation phenomenon as explained in section II. The impact on performances is a longer fall time on the eye diagrams, visible in Fig. 13c-d.

To mitigate this saturation, a first approach illustrated in Fig. 13 consists in further increasing the laser-modulator detuning $\Delta \lambda$. Modulator insertion losses during "1" bit is reduced. And as the $E R(V)$ curve is shifted to higher voltages, a stronger electric field is applied on the modulator MQW, thus reducing the holes sweep-out time. By slightly lengthening modulator section, the extinction ratio can be maintained to the required value. The impact of $\Delta \lambda$ on EML characteristics is illustrated Fig. 13 for a $250 \mu \mathrm{m}$-long EAM, for three $\Delta \lambda$ values separated by $8 \mathrm{~nm}$. Fig. 13a presents the optical spectra for three chips with different detunings of $\Delta \lambda=$ $46 \mathrm{~nm}$ (blue line), $\Delta \lambda=54 \mathrm{~nm}$ (green line) and $\Delta \lambda=62 \mathrm{~nm}$ (red line), respectively. All measurements are realized with the same conditions $\left(\mathrm{I}_{\text {laser }}=70 \mathrm{~mA}\right.$ at $\left.45^{\circ} \mathrm{C}\right)$. Fig. $13 \mathrm{~b}$ shows the 

including reprinting/republishing this material for advertising or promotional purposes, creating new collective works, for resale or redistribution to servers or lists, or reuse of any copyrighted component of this work in other works.

laser facet power as a function of the laser current for three chips with different detunings at $\mathrm{V}_{\mathrm{EAM}}=0 \mathrm{~V}$. We observe highest power for the highest detuning, red line, due to reduced insertion losses. The eye diagrams at a modulation bit rate of $10 \mathrm{~Gb} / \mathrm{s}$, measured with $\mathrm{I}_{\text {laser }}=150 \mathrm{~mA}$ at $45{ }^{\circ} \mathrm{C}$, for low $(\Delta \lambda=46 \mathrm{~nm})$, medium $(\Delta \lambda=54 \mathrm{~nm})$ and high $(\Delta \lambda=62 \mathrm{~nm})$ detunings are represented in Fig. 13c, d and e, respectively. The eye diagrams of the EMLs with low and medium detuning are distorted by the modulation saturation phenomenon (Fig. $13 \mathrm{c}-\mathrm{d}$ ), in particular with a slower fall time. As illustrated in Fig. 13e, the EML with highest detuning $(\Delta \lambda=62 \mathrm{~nm})$ presents a clean eye diagram with a $\mathrm{P}_{\text {ave }}$ of $10.6 \mathrm{dBm}$ and a DER of $11.6 \mathrm{~dB}$, without saturation effect, compatible for class E1. This eye diagram is achieved using a modulator voltage of $2.9 \mathrm{~V}$.
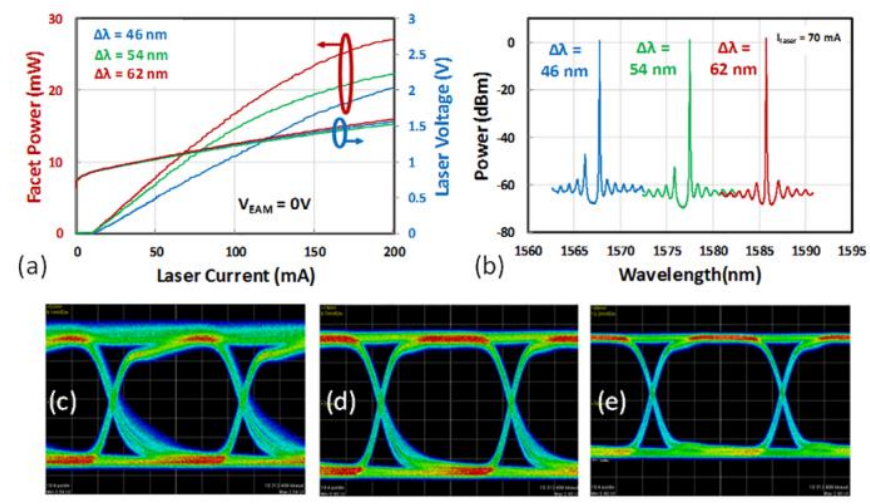

Fig. 13. Study at $45{ }^{\circ} \mathrm{C}$ of performances of EMLs with $250 \mu \mathrm{m}$-long EAM, and different laser-modulator detunings $\Delta \lambda$ of $46 \mathrm{~nm}$ (blue), $54 \mathrm{~nm}$ (green) and $62 \mathrm{~nm}$ (red). (a) Facet power and laser voltage as a function of the laser current at $\mathrm{V}_{\text {EAM }}=0 \mathrm{~V}$ (b) Optical spectrum for three chips with different detunings with $\mathrm{I}_{\text {laser }}=70 \mathrm{~mA}$. $10 \mathrm{~Gb} / \mathrm{s}$ eye diagrams at $\mathrm{I}_{\text {laser }}=150 \mathrm{~mA}$ (c) for $\Delta \lambda=46 \mathrm{~nm}$ obtaining DER $=13.5 \mathrm{~dB}$ and $\mathrm{P}_{\mathrm{ave}}=7.3 \mathrm{dBm}$ with $\mathrm{V}_{\mathrm{pp}}=2.5 \mathrm{~V}$. (d) $\Delta \lambda=54 \mathrm{~nm}$ reaching DER $=12.4 \mathrm{~dB}, \mathrm{P}_{\mathrm{ave}}=9.9 \mathrm{dBm}$ with $\mathrm{V}_{\mathrm{pp}}=2.7 \mathrm{~V}$ and (e) with $\Delta \lambda=62 \mathrm{~nm}$ obtaining $\mathrm{DE} R=11.6 \mathrm{~dB}$ and $\mathrm{P}_{\text {ave }}=10.6 \mathrm{dBm}$ with $\mathrm{V}_{\mathrm{pp}}=2.9 \mathrm{~V}$.

A second approach is to operate the EML at moderate power, but to integrate a Semiconductor Optical Amplifier (SOA) section as a booster after the modulator. This solution eliminates saturation problems in the modulator and can even increase the transmission distance by a chirp compensation effect. Shindo et al. have developed an EML-SOA and demonstrated for $1577 \mathrm{~nm}$ applications with $4.9 \mathrm{~dB}$ of gain provided by the SOA, allowing to reach a $\mathrm{P}_{\text {ave }}$ of $9 \mathrm{dBm}$ [17]. The EML-SOA approach remains delicate because in order to avoid too many perturbations brought by the SOA, it is preferable to operate at least $3 \mathrm{~dB}$ below its saturation regime, which limits the maximum emitted power. In addition, the SOA amplifies the optical feedback, which is very detrimental to the EML. Furthermore, even without optical feedback, the spontaneous emission generated by SOA is modulated by the modulator section and thus may disturb the laser.

A third approach is to modulate both the laser section and the modulator section, with a Laser-Modulated EML (LMEML). During "0", the laser emitting power reduced when the modulator absorbs the light. This limits saturation phenomena since the input power to the modulator is decreased and reduces the power consumption by avoiding unnecessary generation of photons absorbed by the modulator. The limitation of this approach is the requirement for an additional driver for the laser, and the possible degradation of transmission performance due to the direct modulation of the laser. Depending on the applications, in particular on the wavelength range (low chromatic dispersion $\mathrm{O}$-band or $\mathrm{C}$ band) and the bit rate, the modulation ratio between laser and modulator sections can be optimized. For applications at 1577 $\mathrm{nm}$, a gain of $2 \mathrm{~dB}$ in optical power has been demonstrated [18].

\section{EML FOR HIGH-SPEED AND UNCOOLED APPLICATIONS}

The explosive growth of traffic is driving a huge demand for high-capacity data center infrastructure for higher bandwidth. Typical optical interconnects can cover up to 500 meters. Copper direct attach cables are used for connections below $5 \mathrm{~m}$. While between top of rack and leaf level, up to 100-500 m, the multimode active optical cables and transceivers, like VCSELs are widely used. With the increment of distance and requirement for higher data rate, deployment of single mode fiber becomes necessary, either by Parallel Single Mode 4-channel (PSM4), coarse wavelength division multiplexing (CWDM), or local area network wavelength division multiplexing (LAN-WDM) technologies. Intra-datacenter connections require low cost (including the transceivers together with the fibers), low power consumption and high bandwidth density. Transmitters must operate uncooled, without any Peltier control, in order to reduce consumption. And the trend is to increase data rates per lane towards $100 \mathrm{~Gb} / \mathrm{s}$ with 56 GBaud PAM4 modulation formats, for which DMLs reach their performance limits, opening the way to uncooled EMLs $\left(20\right.$ to $\left.70{ }^{\circ} \mathrm{C}\right)$.

However, uncooled operation is particularly challenging for EML because the laser-modulator detuning $\Delta \lambda$ decreases rapidly with temperature. At low temperature, the high detuning results in a smooth extinction curve and a high $\mathrm{V}_{\mathrm{pp}}$. At high temperature, the detuning is low, leading to high insertion loss of the EAM. Thus, it is desired to have a very steep extinction curve to maintain low $V_{p p}$ and high power over a broad temperature range

Aluminium-based MQWs are widespread used for very high temperature operation, both for laser and modulator sections, due to their stronger electron confinement in the conduction band [5], [6]. However, for temperature ranges up to $70^{\circ} \mathrm{C}$, Phosphorus-based MQWs with high bandgap energy barriers can remain performant [7].

For these high-speed intra-datacenter connections, CWDM O-band EMLs are generally deployed. But for short distances, CWDM C-band EMLs could be of interest as well, to increase the number of available channels. Almae demonstrated functional uncooled EMLs working in both C-band [19] and recently extended it to O-band.

\section{A. C-band uncooled EML}

As illustrated Fig. 14a, laser Bragg wavelength shifts with temperature by $0.1 \mathrm{~nm} /{ }^{\circ} \mathrm{C}$, much slower than laser maximum gain which shifts by $0.6 \mathrm{~nm} /{ }^{\circ} \mathrm{C}$ due to semiconductor crystal dilatation. Therefore, the laser photoluminescence is chosen to 

or lists, or reuse of any copyrighted component of this work in other works.

have a positive detuning of Bragg wavelength at $20^{\circ} \mathrm{C}$, which becomes null around $50{ }^{\circ} \mathrm{C}$, and slightly negative at $70^{\circ}$ (SMSR remains above $45 \mathrm{~dB}$ for all temperatures).

Fig. 14b plots the facet power versus pulsed laser current, with the EAM connected to ground. Thanks to the initial positive laser Bragg detuning, and to the high detuning $\Delta \lambda$, facet power remains at $7.5 \mathrm{~mW}$ for laser operating at $150 \mathrm{~mA}$ / $70{ }^{\circ} \mathrm{C}$. (The $\mathrm{C}$-band EML mentioned here is based on modulator length of $150 \mu \mathrm{m})$.

Fig. 14c corresponds to the EAM extinction curve for 70 $\mathrm{mA}$ laser current. Similar to laser gain, the EAM absorption front wavelength shifts by $0.6 \mathrm{~nm} /{ }^{\circ} \mathrm{C}$ while $\mathrm{DFB}$ wavelength shifts by only $0.1 \mathrm{~nm} /{ }^{\circ} \mathrm{C}$, leading to a $\Delta \lambda$ reduction of 0.5 $\mathrm{nm} /{ }^{\circ} \mathrm{C}$. For operation between 20 to $70{ }^{\circ} \mathrm{C}$, it corresponds to a $\Delta \lambda$ variation as large as $25 \mathrm{~nm}$. The EAM stack optimization and the choice of a high $\Delta \lambda$ provide an optimum trade-off with still steep extinction curve at $20{ }^{\circ} \mathrm{C}$, and moderate insertion loss at $70^{\circ} \mathrm{C}$.

We studied the uncooled behavior of our EMLs with 28 $\mathrm{Gb} / \mathrm{s} \mathrm{NRZ}$ modulation, focusing on reducing $\mathrm{V}_{\mathrm{pp}}$ and increasing output power.

Fig. $14 \mathrm{~d}$ shows the electro-optical bandwidth for temperature ranging between $20^{\circ} \mathrm{C}$ and $70{ }^{\circ} \mathrm{C}$. Laser current is fixed at $100 \mathrm{~mA}$ and EAM bias at $-0.5 \mathrm{~V}$. The dip observed at $13 \mathrm{GHz}$ is attributed to the submount design. The intrinsic bandwidth varies between $18 \mathrm{GHz}$ and $20 \mathrm{GHz}$.
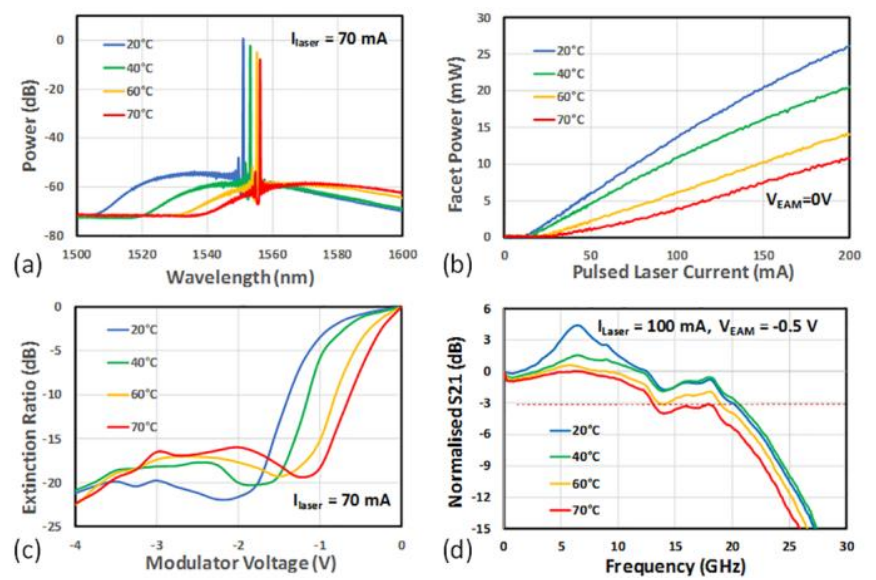

Fig. 14. Characteristics from $20{ }^{\circ} \mathrm{C}$ to $70{ }^{\circ} \mathrm{C}$ of a C-band EML chip on submount. (a) Optical spectra, (b) L(I) curve with pulsed current source, (c) static ER at $\mathrm{I}_{\text {laser }}=70 \mathrm{~mA}$. (d) Electro-Optical bandwidth at $\mathrm{I}_{\text {laser }}=100 \mathrm{~mA}$ and $\mathrm{V}_{\mathrm{EAM}}=-0.5 \mathrm{~V}$.

As illustrated Fig. 15, we collected $28 \mathrm{~Gb} / \mathrm{s}$ NRZ eye diagrams at $20{ }^{\circ} \mathrm{C}, 40{ }^{\circ} \mathrm{C}, 60{ }^{\circ} \mathrm{C}$ and $70{ }^{\circ} \mathrm{C}$. For each temperature, we tested operation for different values of $\mathrm{V}_{\mathrm{pp}}$ $(0.9 \mathrm{~V}, 1.2 \mathrm{~V}$, and 1.6 V), and adjusted on-state EAM voltage $\mathrm{V}_{\text {on }}$ to obtain highest output power while keeping optimal eye opening with $50 \%$ crossing point. Laser is biased at $70 \mathrm{~mA}$, $100 \mathrm{~mA}$ or $150 \mathrm{~mA}$ to maintain high output power, especially at high temperature. The output power after modulation is collected in the fiber and corrected by the measured fiber coupling loss of $3.9 \mathrm{~dB}$ to assess modulated facet power $\mathrm{P}_{\text {ave }}$.

It should be noted that thermal contact is not optimum for this test configuration on submount, compared to operation in module. Laser thermal resistance of $65{ }^{\circ} \mathrm{C} / \mathrm{W}$ is measured: results at $70{ }^{\circ} \mathrm{C} / 150 \mathrm{~mA}$ are pessimistic as they correspond to laser chip temperature of about $83{ }^{\circ} \mathrm{C}$.

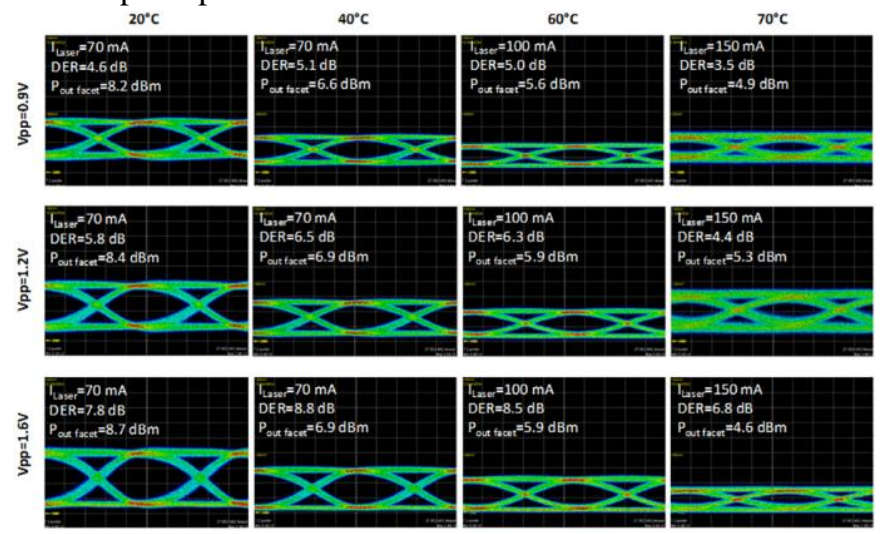

Fig. 15. $28 \mathrm{~Gb} / \mathrm{s}$ eye diagrams at $20{ }^{\circ} \mathrm{C}, 40{ }^{\circ} \mathrm{C}, 60^{\circ} \mathrm{C}$ and $70{ }^{\circ} \mathrm{C}$ with $\mathrm{Vpp}$ equal to $0.9 \mathrm{~V}, 1.2 \mathrm{~V}$ and $1.6 \mathrm{~V}$.

Clear eye openings are obtained for all temperatures. Eye diagrams at $70{ }^{\circ} \mathrm{C}$ appear slightly noisier due to lower input power into the oscilloscope. The temperature dependence of DER and $\mathrm{P}_{\text {ave }}$ are summarized in Fig. 16. From $20{ }^{\circ} \mathrm{C}$ to 70 ${ }^{\circ} \mathrm{C}$, DER of more than $3.5 \mathrm{~dB}$ is obtained even with $\mathrm{V}_{\mathrm{pp}}$ of 0.9 $\mathrm{V}$, and over $6.7 \mathrm{~dB}$ with $\mathrm{V}_{\mathrm{pp}}$ of $1.6 \mathrm{~V}$. $\mathrm{P}_{\text {ave }}$ ranges between about $8.5 \mathrm{dBm}$ at $20{ }^{\circ} \mathrm{C} / 70 \mathrm{~mA}$ and $5 \mathrm{dBm}$ and at $70{ }^{\circ} \mathrm{C} / 150$ $\mathrm{mA}$.
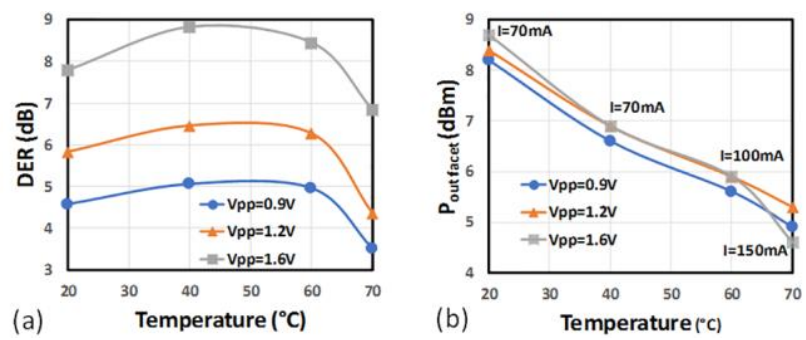

Fig. 16. Summary of temperature dependence of (a) dynamic extinction ratio, (b) facet modulated output power.

\section{B. O-band uncooled EML}

Recently, we have deployed uncooled EMLs for O-band as well. We tried to further improve the output power at high temperature, and the bit rate for 56 GBaud [20]. To optimize the thermal performances of our Phosphorus-based laser MQWs, we used several solid source of Indium and/or Gallium during GSMBE growth to add limited but appreciable degrees of freedom on the In / Ga ratio between the well and the barrier. This allows us to tailor the MQWs band structure and reach a $55 \%: 45 \% \Delta \mathrm{E}_{\mathrm{C}} / \Delta \mathrm{E}_{\mathrm{V}}$, closer to Al-based systems. We utilized this laser structure together with modulator length of $125 \mu \mathrm{m}$ to demonstrate the following device performance. Fig. 17a plots the emitted spectra with temperature with almost zero detuning between laser maximum gain and Bragg wavelength around $45^{\circ} \mathrm{C}$. Fig. $17 \mathrm{~b}$ illustrates facet power curves versus pulsed laser current. Higher output power is observed from $20{ }^{\circ} \mathrm{C}$ to $70{ }^{\circ} \mathrm{C}$ compared to the performance of above-mentioned $\mathrm{C}$-band uncooled EML, thanks to the lower Inter-Valence Band Absorption (IVBA) effect at $1.3 \mu \mathrm{m}$, and to the introduction of new strained Phosphorus-based material system with larger $\Delta \mathrm{E}_{\mathrm{c}} / \Delta \mathrm{E}_{\mathrm{v}}$. Fig. 17c shows the EAM extinction curve for $70 \mathrm{~mA}$ laser current. The extinction curve could be further optimized 

including reprinting/republishing this material for advertising or promotional purposes, creating new collective works, for resale or redistribution to servers or lists, or reuse of any copyrighted component of this work in other works.

by increasing the number of quantum wells. Electro-optical bandwidth at $20^{\circ} \mathrm{C}$ is shown in Fig. 17 d, with laser current of $100 \mathrm{~mA}$ and modulator bias of $-1 \mathrm{~V}$, showing a $\mathrm{f}_{3 \mathrm{~dB}}$ around 27 GHz.
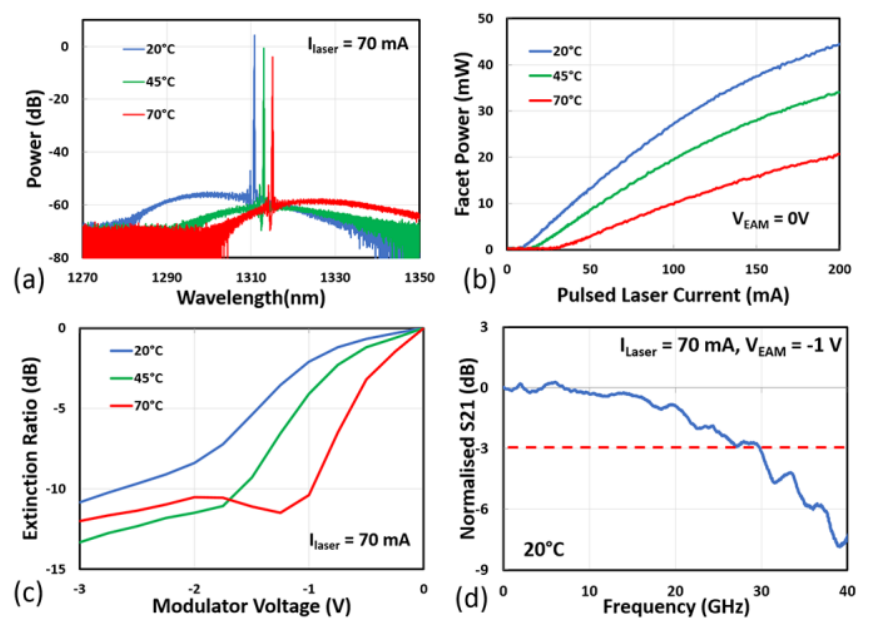

Fig. 17. Static characteristics from $20{ }^{\circ} \mathrm{C}$ to $70{ }^{\circ} \mathrm{C}$ of a C-band EML chip on submount (a) optical spectra, (b) L(I) curve with pulsed current source, (c) static extinction ratio at $\mathrm{I}_{\text {laser }}=70 \mathrm{~mA}$. (d) $\mathrm{S} 21$ at $20^{\circ} \mathrm{C}$ with laser current fixed at $100 \mathrm{~mA}$ and EAM bias of $-0.5 \mathrm{~V}$.

$28 \mathrm{~Gb} / \mathrm{s}$ NRZ eye diagrams were collected at $25{ }^{\circ} \mathrm{C}, 45^{\circ} \mathrm{C}$ and $70{ }^{\circ} \mathrm{C}$ with different $\mathrm{V}_{\mathrm{pp}}$ of $1 \mathrm{~V}, 1.2 \mathrm{~V}$ and $1.5 \mathrm{~V}$. Laser is biased at $30 \mathrm{~mA}, 50 \mathrm{~mA}$ or $100 \mathrm{~mA}$ to maintain high output power. Clear eye openings are obtained for all temperatures (Fig. 18). As for C-band EML measurements, non-optimum thermal contact is not favorable and leads to an increased real temperature chip. DER augments with temperature: lowest DER of $3.9 \mathrm{~dB}$ is observed at $20^{\circ} \mathrm{C}$ with $\mathrm{V}_{\mathrm{pp}}$ of $1 \mathrm{~V}$, while the highest DER of $8.2 \mathrm{~dB}$ is obtained at $70{ }^{\circ} \mathrm{C}$ with $\mathrm{V}_{\mathrm{pp}}$ of $1.5 \mathrm{~V}$. The output power can be maintained above $4.2 \mathrm{dBm}$ for all temperatures by adjusting laser current.
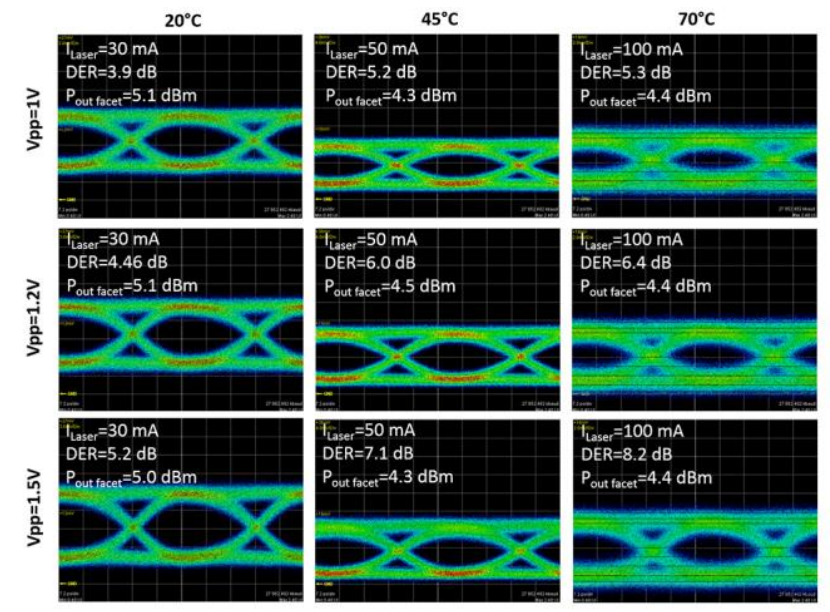

Fig. $18.28 \mathrm{~Gb} / \mathrm{s}$ eye diagrams at $20^{\circ} \mathrm{C}, 45^{\circ} \mathrm{C}$, and $70{ }^{\circ} \mathrm{C}$ with $\mathrm{V}_{\mathrm{pp}}$ equal to 1 $\mathrm{V}, 1.2 \mathrm{~V}$ and $1.5 \mathrm{~V}$.

Fig. 19 shows the relationship between modulator length and DER at the fixed laser current of $50 \mathrm{~mA}$ and temperature of $45^{\circ} \mathrm{C}$. DER is increasing linearly with increased modulator length at all $\mathrm{V}_{\mathrm{pp}}$. The $\mathrm{f}_{3 \mathrm{~dB}}$ has also been measured, showing around $27 \mathrm{GHz}$ for EAM length of $125 \mu \mathrm{m}$, and around 31 $\mathrm{GHz}$ for length of $100 \mu \mathrm{m}$. Thus, it is expected to have a functional EML for 56 Gbaud PAM4 with modulator length around $75 \mu \mathrm{m}$, while the DER can be further optimized by slightly increasing the number of QWs in modulator. Besides, the compatibility with very low $\mathrm{V}_{\mathrm{pp}}$ offers the possibility to integrate the modulator directly with CMOS circuit for further power consumption reduction.

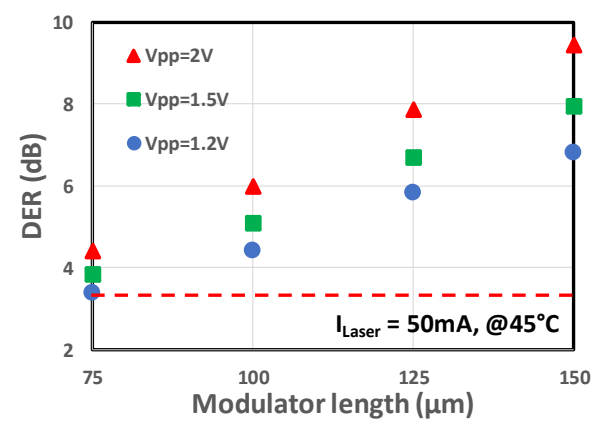

Fig. 19. Relationship between modulator length and dynamic extinction ratio at different $\mathrm{V}_{\mathrm{pp}}$.

\section{EMLS IN SUBASSEMBLY AND FURTHER DEVELOPMENTS}

The tremendous growth of data traffic drives the technology to higher modulation speed and multi-level modulation (56 GBaud PAM4), and to transmitters parallelization with $4 \times 50$ GBaud PAM4 for $400 \mathrm{~Gb} / \mathrm{s}$ or $8 \times 50$ GBaud for $800 \mathrm{~Gb} / \mathrm{s}$ transmitters. Beyond exploiting the performance of EML chip, the optimization of the module packaging is also highly critical, to ensure efficient thermal dissipation, high-speed HF driving to the EAM, and low-cost / high yield assembly techniques.

In a standard approach, the EMLs are soldered on individual submounts with wire bondings for electrical connections as illustrated Fig. 4. However, the parasitic inductance induced by the bonding wire degrades the electrical characteristics of the EA modulator modules in the high-frequency region which becomes highly detrimental for 56 GBaud modulation rates [21]. Then each EML is coupled to the output fiber via accurate positioning of lenses and isolators. This operation is so critical and time consuming that more than $90 \%$ of a transmitter price is due to packaging.

Multiple laboratories have worked on more efficient assembly solutions, generally based on arrays of EMLs monolithically integrated on the same substrate, and on the use of flip-chip technology rather than soldering by the chip bottom side to improve HF performances [22], [23], [24].

We are developing as well, in the frame of a European project APPLAUSE, a flip-chip assembly for 4 uncooled 56 GBaud EMLs, enabling passive optical alignment with Silicon Photonics waveguides. An array of 4 EMLs is flip chipped on a Silicon submount with HF lines, connected by direct soldering to the electrodes. This enables to finely optimize the whole HF line (including the EAM section) for the most efficient transmission of HF electrical signal from the driver to the EAM.

Thanks to the SIBH technology and direct soldering of laser and modulator sections, the thermal dissipation is optimum, enabling to reduce each device self-heating, and thermal crosstalk between adjacent EMLs. 

including reprinting/republishing this material for advertising or promotional purposes, creating new collective works, for resale or redistribution to servers or lists, or reuse of any copyrighted component of this work in other works.

In addition, a specific process has been defined to passively align the EML waveguides with optical fibers accurately positioned into grooves etched on the submount (Fig. 20). To ensure perfect alignment, mechanical recesses in $\mathrm{X}, \mathrm{Y}$ and $\mathrm{Z}$ directions are processed on the EML chip, together with waveguide definition, and corresponding stoppers are defined on the Silicon submount together with fiber $\mathrm{V}$-grooves definition. Owing to the AuSn soldering attraction strength, the EML chip recesses are automatically positioned against the corresponding silicon stoppers, leading to automatic passive alignment. This approach represents a great step forward to reach high yields, low costs, and high performances.

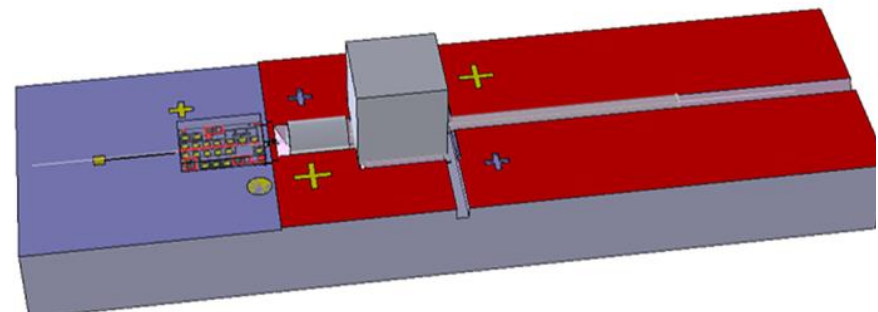

Fig. 20. 3D schematic of a submount with the EML chip, optical interface and $\mathrm{V}$-groove for fiber.

\section{CONCLUSION}

We have demonstrated uncooled $28 \mathrm{~Gb} / \mathrm{s} \mathrm{C}$-band and Oband EML with Phosphorus-based MQWs, butt-joint and SIBH technologies. Through the design of modulator MQW structure, doping profile control, and detuning DFB-EAM between the Bragg wavelength and modulator absorption edge, we obtained a steep modulator extinction curve and high output power. These results are promising for high-speed intra-datacenter transmissions.

\section{ACKNOWLEDGEMENT}

We would like to acknowledge the whole team of Almae Technologies which has contributed to the development of these EMLs. And we would like to acknowledge the European Commission as well for their support in the project APPLAUSE, and our partners, in particular Charles-Alix Manier and Hermann Oppermann from IZM Fraunhofer Institute for their work on self-aligned assembly.

\section{REFERENCES}

[1] N. Sasada et al., "Wide-Temperature-Range $\left(25^{\circ} \mathrm{C}\right.$ to $\left.80^{\circ} \mathrm{C}\right) 53$-Gbaud PAM4 (106-Gb/s) Operation of $1.3 \mu \mathrm{m}$ Directly Modulated DFB Lasers for 10-km Transmission," in 2018 European Conference on Optical Communication (ECOC), 2018, pp. 1-3.

[2] A. M. Fox, D. A. B. Miller, G. Livescu, J. E. Cunningham, and W. Y. Jan, "Quantum well carrier sweep out: relation to electroabsorption and exciton saturation," IEEE Journal of Quantum Electronics, vol. 27, no. 10, pp. 2281-2295, 1991.

[3] C. Silfvenius, G. Landgren, and S. Marcinkevicius, "Hole distribution in InGaAsP $1.3 \mu \mathrm{m}$ multiple-quantum-well laser structures with different hole confinement energies," IEEE Journal of Quantum Electronics, vol. 35, no. 4, pp. 603-607, 1999.

[4] T. Sizer et al., "Measurement of carrier escape rates, exciton saturation intensity, and saturation density in electrically biased multiplequantum-well modulators," IEEE Journal of Quantum Electronics, vol. 30, no. 2, pp. 399-407, 1994.
[5] W. Kobayashi et al., "Design and Fabrication of 10-/40-Gb/s, Uncooled Electroabsorption Modulator Integrated DFB Laser With Butt-Joint Structure," Journal of Lightwave Technology, vol. 28, no. 1, pp. 164$171,2010$.

[6] S. Makino et al., "Uncooled Electroabsorption Modulator Integrated DFB Laser," in OFC/NFOEC 2008 - 2008 Conference on Optical Fiber Communication/National Fiber Optic Engineers Conference, 2008, pp. $1-3$.

[7] Y. Nakai et al., "Uncooled Operation of 53-GBd PAM4 (106-Gb/s) EA/DFB Lasers With Extremely Low Drive Voltage With 0.9 Vpp," Journal of Lightwave Technology, vol. 37, no. 7, pp. 1658-1662, 2019.

[8] P. Byeong Hoon et al., "Investigation of optical feedback in high-speed electroabsorption modulated lasers with a window region," IEEE Photonics Technology Letters, vol. 17, no. 4, pp. 777-779, 2005.

[9] Y. Kwon, J. Choe, J. Sim, S. Kim, H. Yun, and K. Choi, "HighFrequency Characteristics of $40 \mathrm{~Gb} / \mathrm{s}$ Electroabsorption ModulatorIntegrated DFB Lasers: Effect of Traveling-Wave Electrode and Tilted Facet," in 2007 Asia-Pacific Microwave Conference, 2007, pp. 1-4.

[10] E. J. Skogen et al., "Monolithically integrated active components: a quantum-well intermixing approach," IEEE Journal of Selected Topics in Quantum Electronics, vol. 11, no. 2, pp. 343-355, 2005.

[11] D. C. Houghton, M. Davies, and M. Dion, "Limits of strain compensation in MQW InGaAsP/InP 1.5 /spl mu/m lasers," in 1993 (5th) International Conference on Indium Phosphide and Related Materials, 1993, pp. 187-190.

[12] J. Decobert, G. Binet, A. Maia, P.-Y. Lagrée, and C. Kazmierski, "AlGaInAs MOVPE selective area growth for photonic integrated circuits," Advanced Optical Technologies, vol. 4, no. 2, pp. 167-177, 20152015.

[13] U. M. Gosele, "Fast Diffusion in Semiconductors," Annual Review of Materials Science, vol. 18, no. 1, pp. 257-282, 1988.

[14] H. Debrégeas et al., "Record 6dBm electroabsorption modulated laser for $10 \mathrm{~Gb} / \mathrm{s}$ and $25 \mathrm{~Gb} / \mathrm{s}$ high power budget access networks," in 2017 Optical Fiber Communications Conference and Exhibition (OFC), 2017, pp. 1-3.

[15] N. Derek, "PON Roadmap," J. Opt. Commun. Netw., vol. 9, no. 1, pp. A71--A76.

[16] "10-gigabit-capable symmetric passive optical network(XGS-PON)," ITU-T Recommendation G.9807.1, June 2016.

[17] T. Shindo et al., "High Modulated Output Power Over $9.0 \mathrm{dBm}$ With 1570-nm Wavelength SOA Assisted Extended Reach EADFB Laser (AXEL)," IEEE Journal of Selected Topics in Quantum Electronics, vol. 23, no. 6, pp. 1-7, 2017.

[18] I. Cano, D. Nesset, and R. Brenot, "Increasing the modulated output power from an EML transmitter through a novel dual-drive scheme," in 45th European Conference on Optical Communication (ECOC 2019), 2019, pp. 1-4.

[19] X. Dai, H. Debregeas, T. D. H. Nguyen, F. Lelarge, and J. Gentner, "Uncooled $1.55 \mu \mathrm{m}$ electro-absorption modulated laser at $28 \mathrm{~Gb} / \mathrm{s}$ with high power and low Vpp for datacom," in 45th European Conference on Optical Communication (ECOC 2019), 2019, pp. 1-4.

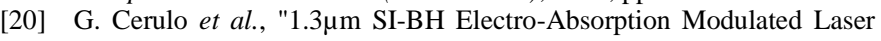
Operating at 56Gbauds/s with $8.4 \mathrm{~dB}$ Dynamic Extinction Ratio," in 2018 European Conference on Optical Communication (ECOC), 2018, pp. 1-3.

[21] T. Hatta et al., "Inductance-controlled electroabsorption Modulator modules using the flip-chip bonding technique," Lightwave Technology, Journal of, vol. 23, pp. 582-587, 03/01 2005.

[22] T. Ohyama et al., "Compact Hybrid Integrated 100-Gb/s Transmitter Optical Sub-Assembly Using Optical Butt-Coupling Between EADFB Lasers and Silica-Based AWG Multiplexer," Journal of Lightwave Technology, vol. 34, no. 3, pp. 1038-1046, 2016.

[23] S. Kanazawa et al., "214-Gb/s 4-PAM Operation of Flip-Chip Interconnection EADFB Laser Module," Journal of Lightwave Technology, vol. 35, no. 3, pp. 418-422, 2017.

[24] S. Kanazawa et al., "Flip-Chip Interconnection Technique for Beyond $100-\mathrm{Gb} / \mathrm{s}(4 \times 25.8-\mathrm{Gb} / \mathrm{s})$ EADFB Laser Array Transmitter," Journal of Lightwave Technology, vol. 34, no. 2, pp. 296-302, 2016. 

including reprinting/republishing this material for advertising or promotional purposes, creating new collective works, for resale or redistribution to servers or lists, or reuse of any copyrighted component of this work in other works.

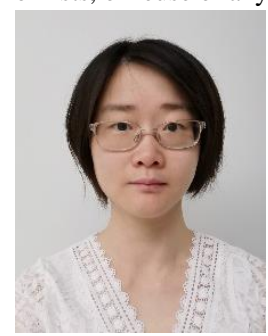

Xing Dai has received her $\mathrm{PhD}$ in the Department of Physics and Applied Physics from Nanyang Technological University, Singapore, in 2014. In the same year, she joined the Institut d'Electronique Fondamentale, France, as a Post-Doctoral Researcher. Her work was focused on the study of III-V and III-N semiconductor nanoscale devices, including FinFET, photodetector and LED. In 2016, she joined Almae Technology as a research development engineer, focusing on the design and technology development of EML devices.

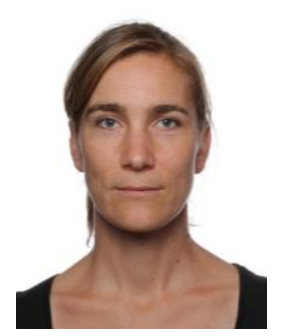

Hélène Debrégeas received Engineering degree from Telecom ParisTech in 1994, Mathematics Agrégation teaching certificate in 1995, and Ph.D on widely tunable lasers in 2007. Since 1997 she has worked at Alcatel Research center (now Nokia Bell Labs, within III-V Lab) on InP transmitters such as electro-absorption modulated lasers, widely tunable laser, and hybrid integration of InP transmitters and silica passive waveguides. Since 2018 she has joined Almae Technologies to develop next generation products and their hybridization with other technologies or packaging. She contributed to more than 50 peer-reviewed journal and conference papers, 20 patents, and a Springer book chapter on widely tunable lasers.

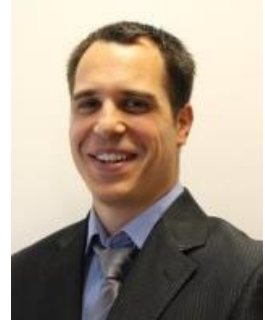

Guillaume Da Rold has been working with Almae since June 2017 as production manager and cleanroom R\&D engineer. $\mathrm{He}$ works on the manufacturing and development of EML 10G. He obtained his $\mathrm{PhD}$ in process engineering in 2009 from the Pierre and Marie Curie University. During his thesis, he worked on the ageing of materials for space applications. Between 2010 and 2011, he worked on laser component fabrication at the III-V lab. Then he worked for 5 years in a start-up called Klearia on the fabrication of glass microfluidic chips for real-time monitoring of pollutants in water.

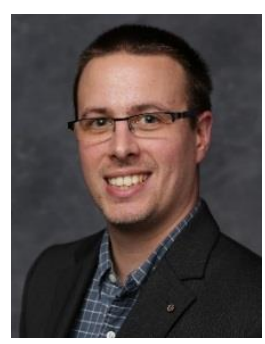

David Carrara received in 2008 his Master degree in Materials and Nanotechnologies from INSA Rennes. From 2009 to 2012, he has pursued a Ph.D. at III-V Lab where he developed new Photonic Integrated Circuits on InP for the generation of advanced modulation formats. In 2012, he joined, as the first employee, the startup Prestodiag in order to develop and industrialize a new optical technology based on Surface Plasmon Resonance to detect pathogen bacteria in the food market. In 2015, he signed up in III-V Lab to study the conception and fabrication of Silicon Photonic Circuits. Since 2017, he has been working for Almae Technologies where he manages a R\&D team working on fabricating high speed
Laser sources. Today, Mr. Carrara holds two patents, one in Optoelectronics and one in Biotechnologies.

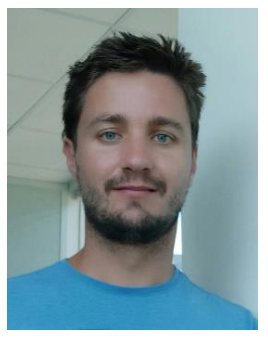

Kevin Louarn received his M.Sc. degree in Material Science from the Grenoble INP Institute of Engineering, France in 2014. He then received his Ph.D degree from Laboratory of Analysis and Architecture of Systems of Toulouse, France in 2018. His Ph.D work was focused on the numerical simulation, the epitaxial growth by MBE, the technological fabrication and the characterisation of tunnel junction and high efficiency multi-junction solar cells based on GaAs substrates. He has been working as a R\&D engineer in MBE at Almae Technologies since 2018.

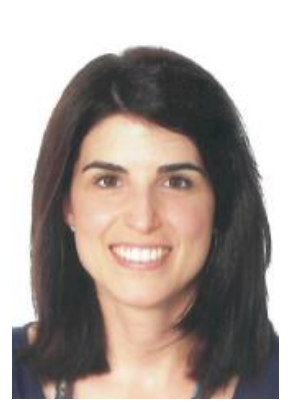

Elena Durán Valdeiglesias received her B. Sc degree in Telecomunications Engineering and her Master's degree from Universidad de Málaga. She received her $\mathrm{Ph}$. D. degree in physics from the University Paris-Saclay in 2019, on the integration of carbon nanotubes onto silicon photonic circuits for the realization of active devices. In 2019, she joined Almae Technologies as characterization engineer.

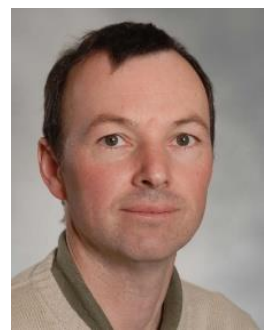

François Lelarge has been working with Almae technologies as the chief technological officer since 2016. He received the Diploma in Material Science in 1993 and the PhD degree in 1996, both from the University of Pierre et Marie Curie, Paris, France. From 1993 to 1996, he was with the Laboratory of Microstructures and Microelectronic, CNRS Bagneux, France. His thesis work was devoted to the fabrication and the optical characterization of GaAs/AlAs lateral superlattice grown on vicinal surfaces by MBE. From 1997 to 2000, he was a postdoctoral researcher at the Institute of Micro and Optoelectronics, Lausanne, Switzerland. He worked on InGaAs/GaAs quantum wires fabrication by MOCVD regrowth on patterned substrates. He was in charge of the Epitaxy and New Material Technology team within III$\mathrm{V}$ Lab and coordinator of a project on QD-based directly modulated lasers (ANR-DIQDOT). He has published more than 300 papers and communications in national and international conferences, including invited talks and postdeadline papers. 